\title{
The Pathway Study of Moulding Children with Healthy Personality in the Modern Horizon
}

\author{
Jian KANG ${ }^{1, a}$, Jianwei $\mathrm{HAN}^{2, b^{*}}$, and Jianxin $\mathrm{JIAO}^{3, \mathrm{c}}$ \\ ${ }^{1.2 .3}$ Hebei Women's Vocational College, Shijiazhuang, He Bei, China \\ a13623115864@163.com, b1982hanwei@163.com, 'jianxinjiao@sina.com
}

\begin{abstract}
The core of family education is to cultivate children with healthy personality. With healthy pesonality, children could have correct self-consciousness, harmonius relationship and good mood controlling ability. Parents should take a pathway to educate their children with healthy personality from building democratic harmonious family, constructing communicatons ability and controlling mood capacity.
\end{abstract}

Keywords: modern horizon children healthy personality analysis

\author{
现代视域中塑造子女健全人格的路径探析 \\ 康健 $^{1, a}$, 韩建伟 $2, b$ 焦建新 $^{3, c}$ \\ 1,2,3河北女子职业技术学院, 石家庄, 河北, 中国 \\ a13623115864@163.com, ${ }^{b} 1982$ hanwei@163. com, , 'jianxinjiao@sina.com \\ *通讯作者:河北省石家庄市南二环汇文街16号
}

中文摘要. 家庭教育的核心是培养子女健全 的人格, 人格健全者有正确的自我意识、和谐的人 际关系和良好的情绪调控能力。父母应从创建民主 和谐家庭、培养交往能力及情绪调控能力等入手培 养子女的健全人格。

\section{关键词：现代视域 子女 健全人格 探析}

\section{1. 引言}

家庭教育是学校教育和社会教育的基 础, 家庭教育的核心内容是让子女学会做 人, 即培养子女健全的人格。人格的成熟意 味着个体心理的成熟, 人格的鬼米力展示着个 体心灵的完善。儿童处于人格塑造的关键时 期, 所以父母要针对子女的身心发展特点因 材施教, 帮助和引导子女塑造健康人格。

\section{2. 塑造子女健全人格的目标}

人格是各种心理特性的一个相对稳定 的组织机构, 是个体的心理面貌, 主要包括
能力、气质、性格、理想、人生观、兴趣、 自我意识等因素。人格是遗传与环境两种因 素交互作用的结果, 不同的遗传、生存及教 育环境, 使得人格诸因素的特征和组合形式 因人而异, 因而个体的人格具有独特性, 即 平时所说的 “百人百性”。由各种心理特征 构成的人格具有稳定性, 如果在没有外部原 因的情况下，一个人的相对稳定性出现问 题, 如一个内向的人变得外向, 那么可能这 个人的心理活动出现了异常。人格影响个体 的思想、感情和行为, “修身、齐家、治国、 平天下”的古训, 说明了健全人格对于个人、 家庭、社会的重要性。父母应了解健全人格 的表现, 及时矫正子女出现的不健全人格。

\section{1 健全人格的表现}

\subsection{1 正确的自我意识}

自我意识是个体对其存在状态的认知, 包括 对自己的生理状态、心理状态、人际关系、 
社会角色等方面的认知。自我意识是社会化 的产物, 是个体与他人、社会群体的相互作 用过程中逐步产生和发展起来的。

具有正确的自我意识的个体自信心强, 能客观评价自己、悦纳自我, 有正确的人生 观与价值观, 对自己有合理客观的期望, 对 生活、学习、工作持乐观积极的态度, 能够 有效地控制和调节自己的思想和行为, 善 于利用每个成长机会改进自己、完善自己。 缺乏正确自我意识的人常常表现出自我冲 突, 有时会放大自己的缺陷, 不珍惜生活。

\section{1.2 和谐的人际关系}

人际关系是人与人在沟通与交往中建 立起来的直接的心理上的联系。人际关系既 是人格健全水平的反映, 同时又影响和制约 着健全人格的形成发展。人格健全的人能够 和社会保持良好、密切的接触, 客观分析、 评价社会现象和问题, 具有较强的社会责任 感和道德原则, 乐于为人所接纳和尊重, 能 与他人建立和谐、良好的人际关系，分享、 给予和接受爱与友谊, 有较多的知心朋友。

\section{1.3 良好的情绪调控能力}

情绪是个体对客观事物主观的有意识 的体验, 是以个体的愿望和需要为中介的一 种心理活动, 具有适应功能、动机功能、组 织功能和信号功能。表情是情绪变化的的外 部表现模式, 包括面部表情、身段表情 (又 称肢体语言) 和言语表情。积极和良好的情 绪有益于人的身心健康, 是人格成熟的标 志。人格健全的个体情绪反应适度, 具有调 节和控制情绪的能力, 能够经常保持愉快、 满意、开朗的心境, 并富有幽默感, 能够恰 如其分地表达自我情绪。当消极情绪出现 时, 能合情合理地渲泄、排解、转移和升华。 能够直面生活、学习、工作中遇到的困难和 挫折, 运用自己的智慧和能力解决问题, 努 力去实现自己的理想目标。

\section{2 不健全人格的表现}

现代社会竞争日益激烈, 社会文化、价 值观念趋向多元化, 生活、学习、工作等方 面的压力不断增加, 这些对构建健全的人格 产生了一定的负面影响。

\section{2 .1 人格缺陷}

人格缺陷是人格的某些特征相对于正常 而言的一种边缘状态或亚健康状态, 是人格 发展的不良倾向, 如自卑、抑郁、怯懦、孤 僻、冷漠、悲观、敏感、焦虑。“人无完人, 金无足赤”, 人格缺陷在正常人身上都有体 现, 可以通过主体努力、外界影响得以矫正。

\section{2 .2 人格障碍}

人格障碍是在没有认知障碍或智力障 碍的情况下, 个体出现的情绪反应、动机和 行为活动的异常, 是一种病态。人格障碍者 的人格特征明显偏离正常, 心理与行为模式 偏离社会文化背景, 明显影响个体的社会功 能和职业功能。人格障碍的治疗是困难的, 应从童年期开始预防。

\section{3. 父母塑造子女人格过程中的失误}

随着社会的进步, 越来越多的父母认识 到了家庭教育的重要性和迫性, “望子成龙, 望女成凤 “, 为子女投入了大量的精力、物 力、财力。由于父母缺乏必要的教育学、心 理学等方面知识, 家庭教育还存在着一些误 区, 教育目标不明确, 影响了子女健康人格 的培养。

\section{1 教育内容方面, 重智轻德}

一些父母只重视子女的智育培养, 把分 数当成智力发展水平的唯一尺度, 热衷于请 家教、上辅导班, 轻视子女的生活能力、道 德品质和实践能力的培养, 在子女成绩不佳 时不能从非智力因素方面分析原因。

一些父母不能很好地根据子女的身心 发展特点、兴趣选择音乐、舞蹈、绘画等方 面的才艺训练, 只注重技术技巧的训练, 忽 视情感、素质的培养, 追求考级、参赛、获 奖等功利性目的, 父母较高的期望值给子女 造成了一定的心理负担。

\section{2 教育方式方面, 表现为溺爱、放纵或专 制等极端方式}

溺爱主要表现为父辈、祖辈无原则地提 供、满足子女物质方面的要求, 包办代替子 女力所能及的事, 袒护子女的过错。放纵型 父母缺乏责任感、爱心, 不关心子女的生活、 
行为、学习、情感, 采取放任自流的态度。 专制型的父母认为对子女的教育就要严厉, 因而不尊重子女的独立人格, 要求子女绝对 服从家长的意志, 采取训斥、辱骂、惩罚甚 至体罚等强制手段干涉和控制子女的行为。

\section{4. 塑造子女健全人格的路径探析}

家庭教育涉及生理学、心理学、教育学 等多方面的知识, 父母作为家庭教育中的主 导者和实施者, 要自觉通过书刊、网络、交 流等各种形式学习把握最新的家庭教育知 识、理念, 了解孩子的身心发展规律和教育 规律, 提高家庭教育的科学性、针对性、实 效性, 通过优化家庭环境, 建立良好的亲子 关系, 言传身教等多种措施, 培养子女健全 的人格, 为子女的社会化历程打下坚实的基 础。

\section{1 创设民主、和谐家庭环境}

家庭结构、家庭关系、家庭气氛、父母 文化素质及社会经济地位、父母教养方式等 都在不同程度上影响着儿童人格的形成与 发展。

夫妻关系是一个家庭是否幸福美满的重 要标志, 夫妻双方应相互尊重、相互支持, 通过文明言行建立和维护威信, 为子女树立 积极的人格榜样。民主、和谐的家庭氛围 能让子女体验到家庭的温暖和幸福, 感受到 亲人的爱, 形成活泼、快乐、自立、森涁有 礼、善于交往等积极的人格品质。父母应坚 持 “教育的一致性” 原则, 对子女的品德、 行为要求协调一致。如果父母观点、标准不 一, 会相互抵消教育效果, 甚至造成孩子思 想上的矛盾或无所适从, 形成两面性格。父 母如果有分歧不要当着孩子的面争吵, 要私 下沟通。

父母要帮助子女树立终身学习的观念, 培养子女浓厚的学习兴趣和良好的学习习 惯, 掌握科学的学习方法, 不强行规定孩子 的学科兴趣、业余爱好。父母要以一颗平常 心对待子女的学习成绩, 和子女一起学习, 建立学习型家庭。父母培养子女的非智力因 素, 是提高子女学习成绩的有效路径。

父母应采取民主型的教育方式, 理解、 尊重子女的人格, 给孩子一定的自主权和积 极正确地指导, 通过奖励、惩罚等教育方法
指导孩子养成好的品行。父母有缺点, 能够 诚既地进行自我批评。父母能够以民主、平 等、开放的姿态与子女沟通、谈心，能够通 过召开家庭会议等形式, 与子女一起平等、 开放地讨论家庭事务, 并共同分担家庭事 务。父母鼓励子女主动参加社会实践, 在实 际行动中培养孩子的文明行为和交往能力。

\section{2 培养孩子良好的人际交往能力}

父母应关注子女的日常交往行为、交往 水平, 适时适当地对其交往技能、技巧、态 度、行为等方面提供帮助和辅导, 培养子女 自主参与各种社交活动的能力, 开朗、合群、 自立的健康人格, 让孩子学会与人和谐共 处、合作共事，建立良好的人际关系。

父母要与家庭成员、邻里、亲友、同事 之间建立和谐的人际关系, 以身示范如何恰 到好处地待人接物。父母可以让子女主动接 待客人, 代父母完成一些力所能及的招待工 作, 如倒茶水、送糖果、搬椅子等。父母可 以在家中举办一些孩子们的聚会, 让子女学 会做小主人, 用自己的食物、玩具和用具招 待伙伴, 体会分享的快乐。父母要扩大子女 的社会生活圈, 鼓励、支持孩子多到社区和 儿童游乐场所参加合作游戏, 积极参加社会 实践活动和学校组织的集体活动, 培养子女 的集体意识, 乐于与人交往的习惯和品质。

父母要营造文明向上的家庭文化、艺术 氛围, 培养子女多方面的兴趣、爱好和特长, 增强子女交往的自信心。父母要培养子女热 情、真诚、包容、文明、谦让等好品质，鼓 励子女广交朋友、善择益友, 把友谊建立在 共同的志趣爱好、互相信任、互相促进的基 础上。父母要培养孩子的礼仪修养, 使用礼 貌用语, 懂得待人接物的礼节。要让子女学 会换位思考, 尊重他人的人格尊严, 不打探 他人的隐私, “己所不欲, 勿施于人。”

\section{3 培养孩子的的情绪调控能力}

父母应关注、尊重、理解子女的情绪, 培养子女丰富自己的情绪体验, 理解和尊重 别人的情绪, 能够适度地表达、控制、调节 自己的情绪, 做自己情绪的主人。

乐观积极的情绪有助于子女智力发展、 自我意识的形成和亲社会行为的产生, 是生 
活、学习、事业顺利发展的基础。成功人士 大多具有稳定的情绪和成熟的心态, 能够做 到处变不惊。良好的情绪源于宽松的教养环 境, 所以父母要为子女创造宽松的心理环 境、物质环境, 充分满足子女的情感需求。 父母要积极进取, 敢于向命运挑战, 多向子 女表达积极情感, 不要在子女面前流露太多 的负面情绪。

由于学习、生活等方面的苦恼和压力, 子女产生适度的、情境性的消极情绪是正常 的。消极情绪持续时间过长, 就会对子女的 身心健康、活动效率、认知发展和人格构建 等方面产生不利的影响。父母要指导子女掌 握合理的调控、宣泄情绪的方式方法。

合理地宣泄。可以向一个值得自己信赖 的人倾诉, 痛快地哭一场, 大声喊叫, 写日 记, 进行大运动量的体育活动等。但应注意 不要对他人、对自己造成伤害。

转移。情绪不佳时可以看喜剧电影电 视、听音乐、看幽默笑话集等, 条件允许, 旅游是一个很好的放松模式。

积极的自我暗示。可以采用语言、行为 进行积极的自我暗示, 心中默念 “我行”、 “我能行”, 微笑、昂首挺胸, 在公众场所 坐在前排惹人注目的地方。主动帮助别人, 完成力所能及的任务, 产生更多积极情绪。

\section{5. 结束语}

总之, “三岁看大, 七岁看老”, 儿童的 早期经验对其人格形成与完善至关重要。子 女是家庭最大的财富, 作为子女第一任老师 和终身老师的父母, 应掌握并践行科学的家 庭教育理念, 积极践行人格教育, 多措并举, 培养子女健全的人格。

\section{References}

[1]Yu Fengyin, Yu Muxin. On the Negative Function of Modern Family Education to Individual Development[J] TianJin Normal University Journal(Elementary Education Edition), 2014(1).

[2]Zhang Liping. On Family Education Model and Children Personality Shapeing[J] Journal ofLanzhou Institute of Education, 2014(2).
[3] Yan Xulei, Yang Ping. New Theory on Family Education $[\mathrm{M}]$. Beijing: Beijing University press, 2012.

[4]Li Yufeng. Contemporary Domestic Urban Family Children Personality Review - The Family of Preschool Children in L City as an Example [D].Luoyang, Henan University Of Science and Technology ,2013.

[5]China Association Mental Health, CETTIC. Psychological Consultant(Basic Knowledge) $[\mathrm{M}]$. Beijing: the Ethnic Publishing House, 2012. 